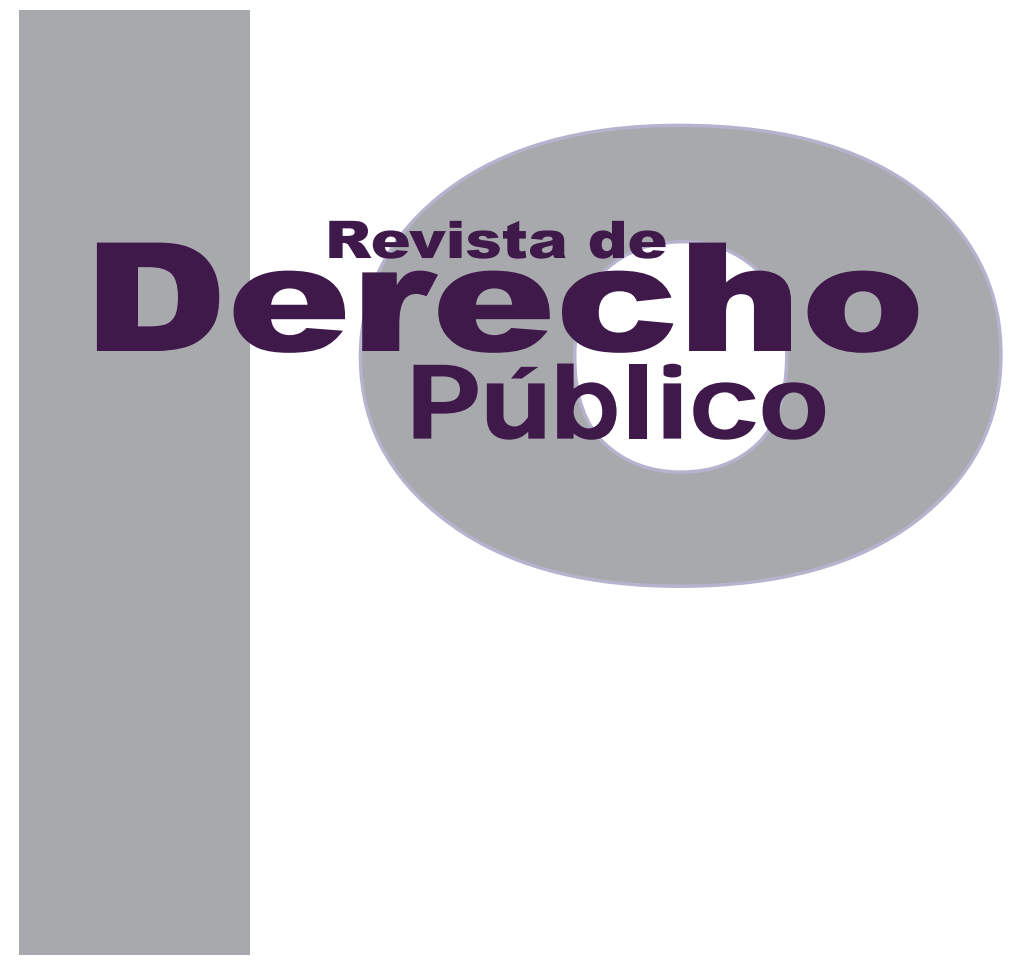

\title{
LA CLÁUSULA DE LA NACIÓN MÁS FAVORECIDA EN LOS TRATADOS BILATERALES DE INVERSIÓN VIGENTES PARA COLOMBIA Y SUS EFECTOS DE ACUERDO CON LOS LAUDOS ARBITRALES DEL CIADI
}

María Clemencia Monroy Hernández

\author{
Artículo de reflexión
}

DOI: http://dx.doi.org/10.15425/redepub.35.2015.07

Universidad de los Andes

Facultad de Derecho

Rev. derecho publico No.35

julio - diciembre de 2015. ISSN 1909-7778 


\title{
La cláusula de la nación más favorecida en los tratados bilaterales de inversión vigentes para Colombia y sus efectos de acuerdo con los laudos arbitrales del CIADI
}

\section{Resumen}

El propósito de esta investigación es analizar los efectos y los riesgos de la aplicación de la cláusula de la nación más favorecida (CNMF), la cual permite que los inversionistas se beneficien de garantías que no fueron incluidas inicialmente en un tratado bilateral de inversión. En particular, se va a demostrar que los efectos dependen de las exclusiones que se realicen en la redacción de la CNMF, y que al tener condiciones más detalladas se puede garantizar de manera más eficiente la seguridad jurídica, ya que se previene que un tribunal de arbitraje extienda los efectos más allá de lo deseado por los Estados. Para desarrollar lo anterior, se contextualizará la situación de la inversión extranjera y los tratados bilaterales de inversión en Colombia, se realizará una revisión conceptual de la cNMF, se analizarán distintas decisiones de tribunales arbitrales del Centro Internacional de Arreglo de Diferencias Relativas a Inversiones (CIADI) y se estudiaran cláusulas particulares de los tratados bilaterales de inversión (твI) firmados por Colombia, haciendo énfasis en los tratados con Estados Unidos y Suiza.

Palabras clave: inversión extranjera directa, tratado bilateral de inversión, cláusula de nación más favorecida, arbitraje internacional de inversión, Centro Internacional de Arreglo de Diferencias Relativas a Inversiones.

\section{The most-favored nation clause in bilateral investment treaties currently in force for Colombia and thier effects in accordance with icsid arbitral awards}

\begin{abstract}
The purpose of this research is to analyze the effects and risks of the application of the most-favored nation (MFN clause), which allows investors to benefit from guarantees, which were not initially included in a bilateral investment treaty. In particular, this work will demonstrate that the effects of this clause depend on the exclusions made in the wording of the MFN clause, and that having more detailed conditions can result in a more efficient guarantee of legal certainty, since it prevents an arbitration tribunal from expanding the effects of the clause beyond what States would desire. To further develop this concept, the paper first puts the situation of foreign investment and bilateral investment treaties in Colombia into context, a conceptual review of the MFN clause is made, various decisions by the International Centre for Settlement of Investment Disputes (ICSID) arbitral tribunals are analyzed and specific clauses of bilateral investment treaties (BITs) signed by Colombia are studied, focusing on treaties with the United States and Switzerland.

Keywords: foreign direct investment, bilateral investment treaty, most favored nation clause, international investment arbitration, International Centre for Settlement of Investment Disputes.

\section{A cláusula da nação mais favorecida nos tratados bilaterais de investimento vigentes para a Colômbia e seus efeitos de acordo com os laudos arbitrais do CIADI}

\section{Resumo}

O propósito desta pesquisa é analisar os efeitos e os riscos da aplicação da cláusula da nação mais favorecida (cNMF), a qual permite que os investidores se beneficiem de garantias que não foram incluídas inicialmente em um tratado bilateral de investimento. Em particular, será demostrado que os efeitos dependem das exclusões que se realizem na redação da CNMF, e que ao ter condições mais detalhadas é possível garantir de maneira mais eficiente à seguridade jurídica, já que é previsto que um tribunal de arbitragem estenda os efeitos além do desejado pelos Estados. Para desenvolver o anterior, será contextualizada a situação do investimento estrangeiro e os tratados bilaterais de investimento na Colômbia, será realizada uma revisão conceitual da CNMF, serão analisadas distintas decisões de tribunais arbitrais do Centro Internacional de Arreglo de Diferenças Relativas a Investimentos (CIADI) e serão estudadas cláusulas particulares dos tratados bilaterais de investimento (TBI) assinados pela Colômbia, dando ênfase nos tratados com os Estados Unidos e com a Suiça.

Palavras-chave: investimento estrangeiro direto, tratado bilateral de investimento, cláusula de nação mais favorecida, arbitragem internacional de investimento, Centro Internacional de Arreglo de Diferenças Relativas a Investimentos. 


\title{
La cláusula de la nación más favorecida en los tratados bilaterales de inversión vigentes para Colombia y sus efectos de acuerdo con los laudos arbitrales del CIADI ${ }^{*}$
}

\author{
María Clemencia Monroy Hernández ${ }^{* *}$
}

\begin{abstract}
SUMARIO
Introducción - I. LOS TRATADOS BILATERALES DE INVERSIÓN EN EL MARCO DE LA PROMOCIÓN DE LA INVERSIÓN EXTRANJERA DIRECTA EN COLOMBIA - A. Inversión extranjera directa en Colombia - 1. Lógica económica - 2. Régimen jurídico - B. Tratados bilaterales de inversión - 1. Concepto y evolución - 2. Contexto colombiano - II. LA CLÁUSULA DE LA NACIÓN MÁS FAVORECIDA EN LOS TRATADOS BILATERALES DE INVERSIÓN - A. Definición - B. Aplicación - C. Categorías - 1. Ámbito de aplicación - 1.1. Objeto de protección - 1.2. Establecimiento - 1.3. Excepciones - 1.4. Cualificaciones - 2. Protección sustantiva - 3. Disposiciones procedimentales - III. LA CLÁUSULA DE LA NACIÓN MÁS FAVORECIDA EN LOS LAUDOS DE TRIBUNALES ARBITRALES INTERNACIONALES - A. Los laudos de los tribunales de arbitraje del CIADI - B. Posiciones sobre la CNMF - 1. Ámbito de aplicación - 2. Excepciones sustantivas - 3. Disposiciones procedimentales - IV. LA CLÁUSULA DE LA NACIÓN MÁS FAVORECIDA EN LOS TRATADOS BILATERALES DE INVERSIÓN VIGENTES PARA COLOMBIA - A. Tratado con EE. UU. - B. Tratado con Suiza - V. CONCLUSIONES - Referencias.
\end{abstract}

* Cómo citar este artículo: Monroy Hernández, M. C. (Diciembre, 2015). La cláusula de la nación más favorecida en los tratados bilaterales de inversión vigentes para Colombia y sus efectos de acuerdo con los laudos arbitrales del cIADI. Revista de Derecho Público, 35. Universidad de los Andes (Colombia).

Escrito presentado como tesis de grado de Derecho. Director de tesis: Álvaro Pereira.

** Abogada Cum Laude y Economista Cum Laude de la Universidad de los Andes. Realizó un semestre de intercambio en la Universidad PanthéonAssas París Il y un curso en Washington College of Law. Actualmente se encuentra realizando una pasantía en la Organización de Estados Americanos. Correos: mc.monroyh@gmail.com; mc.monroy700@uniandes.edu.co 
Introducción

El presente trabajo trata sobre los tratados bilaterales de inversión (TBI) y en particular sobre la cláusula de la nación más favorecida (CNMF) y los alcances que esta puede tener en la práctica. El propósito de la investigación es comparar distintas formas en las que se ha fijado el alcance de la CNMF, para de esta manera lograr una mejor comprensión de los efectos y, por lo tanto, de los riesgos que esta puede acarrear. Se analizará el tema en el contexto colombiano, para lo cual se hará referencia a los TBı vigentes y se estudiará la cláusula en tratados particulares.

La pregunta de investigación es: ¿cuáles son los efectos de la CNMF en los TBI firmados por Colombia a la luz de los laudos de arbitraje internacional del cIAdı? La hipótesis es que los efectos de la CNMF van a depender de los términos utilizados y de las exclusiones que contenga, de hecho si la cláusula es redactada de manera general, el ámbito de aplicación podría ser más amplio y la CNMF se podría extender a disposiciones que las partes no tenían previstas. Las decisiones arbitrales del Centro Internacional de Arreglo de Diferencias Relativas a Inversiones (CIADI) no muestran una visión uniforme respecto del alcance de la CNMF, por lo cual al ser redactada de manera más detallada, incluyendo exclusiones, como lo es aclarar que no aplica respecto de los mecanismos de solución de controversias, se otorga mayor seguridad jurídica en el contexto de incertidumbre.

De acuerdo con lo anterior, se puede identificar que el objetivo general es profundizar en el co- nocimiento sobre los TBı en Colombia, los cuales se pueden ver como un fenómeno reciente con el auge de la inversión extranjera directa (IED). Particularmente, se quiere aportar a la comprensión de la CNMF y de los riesgos que puede tener su redacción al momento de ser interpretada por los tribunales. Los objetivos específicos son: ver cuál ha sido la evolución de la IED en Colombia y su relación con los TBI, identificar cuál es la posición de los tribunales arbitrales internacionales frente a los efectos de la CNMF, comparar el contenido y las exclusiones de la CNMF en los TBI vigentes para Colombia, y proponer recomendaciones que permitan garantizar la seguridad jurídica en la aplicación de la cNMF. Igualmente, se quiere proponer un enfoque de estudio de la CNMF, basado en un análisis más focalizado de las garantías a las cuales se puede extender. Parte de este análisis se concentrará en los tratados específicos que Colombia ha firmado con Estados Unidos (EE. UU.) y Suiza en materia de inversión.

Para desarrollar la pregunta, se iniciará por realizar en el primer capítulo un contexto de la IED y los TBI en Colombia de acuerdo con sus fundamentos jurídicos y económicos; se tendrá en cuenta el papel de la IED en Colombia y los propósitos y evolución de los TBI. En el segundo capítulo se expondrán las principales características de la CNMF, así como la manera en que estas han sido clasificadas y los problemas que presenta su aplicación, teniendo en cuenta las distinciones entre beneficios sustanciales $y$ procedimentales. En el tercer capítulo se analizarán distintos laudos arbitrales en donde los tribunales han tratado el tema de la CNMF, para 
así determinar cuáles son los efectos de la cNMF en el marco del arbitraje internacional de inversión del CIADI. Por último, en el cuarto capítulo se investigará de qué manera se ha redactado la CNMF en los tratados vigentes en los que es parte Colombia, concretamente en el capítulo de inversión del tratado de libre comercio (TLC) con EE. UU. y el TBI con Suiza. De esta manera se podrá ver cuáles son las implicaciones de haberla redactado de una determinada manera, comparándola con otros tratados vigentes para Colombia. Por último, se analizará qué recomendaciones jurídicas se pueden hacer sobre cómo pueden ser pactadas para garantizar seguridad jurídica a las partes.

La metodología que más se ajusta al procedimiento expuesto para desarrollar la pregunta de investigación es el de un análisis dogmático jurídico. Por tanto, este trabajo se concentra en el estudio de las fuentes jurídicas, que en este caso son los tratados internacionales. Igualmente, para lograr una mejor comprensión de la CNMF, se hará un análisis de los laudos arbitrales y la doctrina, con el fin de ayudar a determinar su alcance en un caso concreto. La técnica de recolección de datos será el análisis documental de las fuentes. Al realizar el análisis de los laudos arbitrales se puede tener una visión de cómo se ha aplicado efectivamente en la práctica la CNMF en disputas de inversionistas y Estados.

\section{LOS TRATADOS BILATERALES DE INVERSIÓN EN EL MARCO DE LA PROMOCIÓN DE LA INVERSIÓN EXTRANJERA DIRECTA EN COLOMBIA}

\section{A. Inversión extranjera directa en Colombia}

Para comprender de mejor manera el contexto de los TBI en Colombia debemos empezar por presentar la IED como un fenómeno económico que tiene distintos efectos, al ser una fuente de financiación que impacta la producción y el empleo. Igualmente, el régimen jurídico que regula la IED en Colombia se enmarca en una visión que busca promoverla. A partir de la apertura económica de los años 90 en Colombia, la globalización de la economía ha incluido un aumento en los flujos de IED y se piensa que en los últimos años está en una fase de crear condiciones para atraer IED de mejor calidad (Kalin, 2009).

\section{Lógica económica}

La inversión extranjera se entiende como la "transacción según la cual se adquieren activos por parte de un agente económico por fuera de su propio país" (Agudelo, 1997). Esta se divide en inversión extranjera directa e inversión de portafolio. La IED se refiere a la adquisición de activos productivos de forma directa incluyendo su posesión y control, como lo serían firmas y tierras (Agudelo, 1997). La inversión implica una relación de largo plazo entre la firma que invierte y la receptora cuando se involucra algo más que capital, por ejemplo, control gerencial 
o guía técnica (Kalin, 2009). Por su parte, la inversión de portafolio se compone de la adquisición de activos financieros, bonos, por ejemplo (Agudelo, 1997).

Para comprender el impacto de la IED desde el punto de vista económico se debe tener presente que se trata de una fuente importante de financiación y un determinante significativo de la cuenta corriente y de capital, que ha permitido la acumulación de activos externos, entre los que están las reservas internacionales (Garavito, Iregui y Ramírez, 2012, págs. 35-36). Igualmente favorece la formación de capital y tiene efectos sobre los ingresos fiscales (Garavito et al., 2012, pág. 35).

De acuerdo con la Comisión Económica para América Latina y el Caribe (CEPAL, 2013), en América Latina las empresas transnacionales tienden a promover empleos mejor remunerados y se asocian a niveles más altos de productividad laboral. De igual manera, se ha identificado que Ios flujos de IED permiten el desarrollo del mercado doméstico (Agudelo, 1997). Kalin (2009) habla de los efectos spillover, los cuales se dan al haber una transmisión de tecnología o knowhow, habilidades de mercadeo y experiencia internacional a firmas locales.

Sin embargo, la efectiva mejora en productividad puede depender de los sectores económicos y de las interconexiones con firmas domésticas, por lo cual los gobiernos deben promover políticas para tal fin. También, se debe tener presente que la entrada masiva de capitales puede llegar a producir presiones inflacionarias y procesos de revaluación, lo cual afecta negativamente la economía (Agudelo, 1997). Lo anterior hace que sea necesario coordinar la entrada de capitales extranjeros con el conjunto de políticas económicas del Estado.

El estudio de la IED en Colombia resulta relevante pues en los últimos diez años ha aumentado más de nueve veces (Procolombia, 2015). Hasta mediados de los años 90, la IED se mantuvo por debajo de los 1500 millones de dólares en flujos anuales, y a partir del 2005 se ha mantenido alrededor de los 10000 millones de dólares (Garavito et al., 2012), alcanzando 16000 millones en el 2014 (Procolombia, 2015).

El sector que recibe los mayores flujos de IED es minería y petróleo, representando el $40 \%$ en el 2014, seguido por los sectores de manufacturas y servicios financieros (Procolombia, 2015). Se pueden identificar igualmente políticas sectoriales del gobierno para promover la IED, como lo es en infraestructura (Departamento Nacional de Planeación [DNP], 2011, pág. 201).

Es importante resaltar que Colombia es el cuarto país receptor de inversión en América Latina, después de Brasil, México y Chile; además ocupa el tercer lugar en rentabilidad media (CEPAL, 2013). Esto nos muestra que comparativamente en la región, Colombia representa un destino atractivo de inversión.

\section{Régimen jurídico}

Desde el punto de vista jurídico, la IED se entiende como la transferencia de activos de un Esta- 
do a otro con vocación de permanencia y control, siempre que no haga parte de la inversión de portafolio (Moosa, 2002). La delimitación del concepto puede variar de un instrumento jurídico a otro, pues en los TBI se suele incluir un artículo en el que se describen los componentes que se entienden como inversión. Entre estos encontramos desde la propiedad tradicional, hasta contratos y propiedad intelectual.

En general la IED es realizada por empresas multinacionales que adquieren distintas formas jurídicas. Sin profundizar en este punto, se puede establecer que las formas principales son: (i) greenfield cuando se establece una unidad de producción, distribución u otra actividad económica en el país receptor, (ii) fusiones y adquisiciones con firmas establecidas en el país receptor y (iii) joint-ventures cuando hay asociaciones entre el sector privado extranjero y el Estado del país receptor de la inversión (Moosa, 2002).

El régimen general de la inversión extranjera en Colombia está contenido en el Decreto 2080 de 2000. En este se inicia por definir las inversiones internacionales y se establecen las disposiciones sobre el registro de estas y los derechos cambiarios y garantías para los inversionistas. En cuanto al régimen de cambios internacionales, resultan relevantes la Ley 9 de 1991, el Decreto 444 de 1967, ${ }^{1}$ la Resolución Externa n. ${ }^{\circ}$ 8 de 2000 del Banco de la República y la Circular Reglamentaria Externa DCIN 83 del Departamento de Cambios Internacionales de la misma

1 Este Decreto trata sobre el régimen de cambios internacionales y de comercio exterior. En el artículo segundo se establece que todas las operaciones de cambio exterior están sujetas a control. entidad. Se debe tener en cuenta que algunos sectores tienen regímenes especiales, como lo son hidrocarburos y minería. La normatividad interna es complementada por los TBI, los cuales serán tratados en la siguiente sección.

Las normas que regulan la inversión extranjera se fundamentan en los impactos económicos que se presentaron anteriormente. Es decir, se ha buscado crear un clima más favorable a la inversión a través de la normatividad, e igualmente poder medir sus efectos con el registro cambiario.

Es importante recordar que el entorno jurídico y tributario, y la participación del país receptor en tratados de libre comercio y otros acuerdos internacionales hacen parte de los factores de atracción, o sea los “determinantes presentes en los países receptores que operan atrayendo la IED" (CEPAL, 2013, pág. 11), al igual que otros como el riesgo para la inversión y el desempeño económico (CEPAL, 2013, pág. 12). En este sentido, se ha dicho que "un marco regulatorio y legal que sea estable, transparente y bien definido puede convertirse en un elemento importante para la atracción de IED" (Esquivel y Larraín, 2001). Se habla también de factores institucionales, los cuales incluyen la calidad del sistema legal, respeto por el imperio de la ley o rule of law, riesgo político y otras medidas de calidad institucional (Conferencia de las Naciones Unidas sobre Comercio y Desarrollo [UnCTAD, por sus siglas en inglés], 2009).

Las políticas para promover la IED pueden ser clasificadas en activas, pasivas e integrales 
(CEPAL, 2006). La firma de los TBI se puede entender como una medida pasiva, ya que facilita la inversión al mejorar el marco regulatorio (CEPAL, 2006). Así mismo, se crean mejores condiciones para los inversionistas, pues los tratados permiten un marco regulatorio con reglas predecibles que reducen los riesgos no comerciales de quienes quieren invertir en el país (Garavito et al., 2012, pág. 50), en la medida en que complementan el régimen general de la inversión extranjera. Es decir, los TBı mejoran las condiciones de inversión para los inversionistas extranjeros.

\section{B. Tratados bilaterales de inversión}

Ahora se pasa a presentar los TBI como el principal instrumento del derecho internacional de la inversión extranjera, y sus tendencias tanto en el ámbito internacional como nacional.

\section{Concepto y evolución}

Los TBI O acuerdos bilaterales de promoción y protección recíproca de inversiones (APPRI) son tratados que los Estados firman para dar mayores garantías a los inversionistas de otro Estado, y se enmarcan en una política de fomento de la IED que busca ampliar la seguridad jurídica. Dentro de sus principales efectos están "establecer el trato y protección debidos al inversor extranjero que el Estado receptor se compromete internacionalmente a garantizar (...) otorgar al inversor extranjero el derecho de someter toda controversia con el Estado receptor de capital a una instancia arbitral internacional" (Granato y Nahuel, 2007, pág. 33). Las garantías principa- les consagradas en los TBI son el trato nacional, la CNMF, trato justo y equitativo, protección y seguridad plena y reglas sobre expropiaciones.

Según Lizarazo (1997) estos tratados surgen en el contexto económico del "nuevo orden económico internacional implantado en los años sesenta y consolidado en los setenta" (pág. 93), cuando los países desarrollados buscaban garantías mínimas para realizar sus inversiones en un ambiente seguro. Se puede ver un aumento significativo en la firma de los TBı en la segunda mitad del siglo XX, ya que en la década de 1970 habían 166, en la siguiente década 386, y entre 1990 y 1998 se tuvo un número acumulado de 1726 (UnCtAD, 1999a). Hacia la década de los 70 se desarrollaron instrumentos que establecían guías de conducta para las multinacionales y reafirmaban la soberanía de los países receptores. En las siguientes décadas, debido a los cambios en la economía mundial, cambia la percepción de los procesos de inversión y el debate se centra en las formas más eficientes de atraer la inversión extranjera promoviendo el desarrollo económico de los países (UnCTAD, 1999a). Para la década de los 90 no solo se encuentra que los países desarrollados tienen extensas redes de tratados, sino que países que son pequeños exportadores de capital y países en desarrollo también los han suscrito entre sí (UNCTAD, 1999a). En este sentido, "Si bien los tвı han sido instrumentos legales usados usualmente para regular las relaciones norte-sur, en los últimos años muchos han sido firmados entre países en desarrollo"2 (Bonilla y Castro, 2006, pág. 4).

2 Traducción propia. 
Se debe precisar que un твı puede ser un tratado independiente, o sus disposiciones pueden hacer parte en un tratado más extenso que cubra distintos temas. En tal caso, se trata de un tratado de integración económica e inversión (Economic Integration Investment Agreement -EIIA), que busca facilitar el comercio y las inversiones (UNCTAD, 2006). También se conocen como tratados de libre comercio, acuerdos comerciales regionales o acuerdos de complementación económica (UNCTAD, 2006). En estos puede haber un capítulo en el que se incluyan las cláusulas que se pactarían en un TBI.

Se ha encontrado que los TBI tienen distintas funciones al ser determinantes de la IED: aumentar la protección, liberalización, transparencia, previsibilidad y estabilidad (UNCTAD, 2009, pág. 24). Los tBı son la base de obligaciones tanto sustanciales como procesales para los Estados:

Promueven la previsibilidad y la estabilidad de las normas relativas a la inversión porque establecen obligaciones internacionales jurídicamente vinculantes de las que el país receptor no puede apartarse unilateralmente. También contribuyen a reforzar esta situación los procedimientos internacionales de solución de diferencias entre los inversores y el Estado (UNCTAD, 2009, pág. 24).

Como se puede ver, dentro de las principales ventajas que encontramos en un tBı están los mecanismos de solución de controversias. Los Estados pueden acordar si la solución de diferencias se somete a un tribunal de una institución internacional o a un arbitraje ad hoc, lo cual va a restringir la jurisdicción del Estado receptor de IED para conocer de dichos litigios.
Al suscribir un TBI, el Estado adquiere la obligación internacional de proteger las inversiones, pues de lo contrario no se podría establecer la responsabilidad internacional. En un тв। se puede incluir un acuerdo en el que se acepte la posibilidad de someter las diferencias relativas a inversión al arbitraje internacional. Esto permite que el tribunal tenga jurisdicción en la disputa, ya que el consentimiento del Estado receptor y el Estado del cual el inversionista es nacional es indispensable (Dolzer, 2008).

Es decir, de los TBI surgen obligaciones internacionales para los Estados, que permiten la solución de disputas a través del arbitraje entre Estados e inversionistas que acrediten la nacionalidad del otro Estado firmante. Lo anterior adquiere un carácter sui generis en el derecho internacional. Las cláusulas sobre asuntos de procedimiento que permiten el acceso al arbitraje internacional derogan un principio de la costumbre internacional, de acuerdo con el cual los actos de un Estado deben cuestionarse en primer lugar en su propia jurisdicción y solo podría un Estado demandar a otro Estado una vez agotado el trámite interno (UnCTAD, 2010).

Si no se pacta la posibilidad de acceder a un mecanismo de arbitraje, solo podría recurrirse a los métodos tradicionales de resolución de conflictos, como son la acción en Cortes domésticas y la protección diplomática. Sin embargo, para el inversionista puede no ser atractivo acudir a las Cortes del Estado receptor debido a dudas en la garantía de imparcialidad, falta de especialidad técnica y primacía de los poderes soberanos del Estado (Dolzer, 2008, pág. 214). 
Uno de los foros que se pacta con mayor regularidad en los TBI para el arreglo de controversias es el CIADI. Fue creado en 1965 con el fin de promover el desarrollo económico al propiciar un clima favorable para la inversión, por lo cual provee un sistema de resolución de disputas entre inversionistas y Estados (Dolzer, 2008). El CIADI es una de las cinco instituciones que compone el Grupo del Banco Mundial, aunque sea una organización internacional autónoma del Banco Mundial (World Bank, 2011).

\section{Contexto colombiano}

Los TBI se enmarcan en un régimen jurídico de la inversión extranjera que se ha transformado de acuerdo con la evolución de la política de IED en Colombia. Se puede identificar que entre las décadas de 1960 y 1990 se caracterizaba por altas restricciones a los flujos de capital (Universidad del Rosario, 2006). Lo anterior se daba en el marco de la política de sustitución de importaciones, la cual buscaba fortalecer la industria interna adoptando medidas proteccionistas y promoviendo la producción para exportar. Posteriormente, en la década de los 90 se adoptan ciertas reformas estructurales orientadas a la liberalización del comercio y a la promoción de la entrada de capitales (Universidad del Rosario, 2006). Una de las políticas para materializar lo anterior fue firmar los TLC y TBI, entre otros tipos de tratados internacionales. ${ }^{3}$

3 Por ejemplo, entre 1994 y 1995 se firmaron los TBI con Reino Unido, Cuba, Perú y España. Sin embargo estos fueron declarados inexequibles por la Corte Constitucional debido a lo establecido sobre la indemnización por expropiaciones. En 1999 fue necesario también un proceso de renegociación como consecuencia de una reforma constitucional (Universidad del Rosario, 2006).
De la misma manera, los gobiernos posteriores han continuado con esta tendencia para incentivar la IED en Colombia.

Actualmente, de los doce tratados vigentes ocho entraron en vigor en el 2011, compuestos tanto por TBI como por TLC con capítulos de inversión (Ministerio de Comercio, Industria y Turismo [MCIT], 2014). El primer tratado que entró en vigencia fue el TLc firmado con México, en 1995. ${ }^{4}$ Posteriormente empezaron a regir: en el 2007 el APPRI con España; en el 2009 el TBI con Suiza, el TLC con Chile y el TLC del Triángulo Norte con Guatemala; desde el 2010 el TLc del Triángulo Norte con Salvador y Honduras; en el 2011 el TBI con Perú y con Canadá y el TLC con los países del AELC para Suiza y Liechtenstein; en el 2012 el TLC con EE. UU. y los TBI con China e India (MCIT, 2014); y en octubre de 2014 el Acuerdo Bilateral para la Promoción y Protección de Inversiones de Colombia y Reino Unido.

Para ilustrar la evolución de la política frente a la IED se puede hacer una remisión al Plan Nacional de Desarrollo 2002-2006 ${ }^{5}$ en el que se “planteó la suscripción de tratados bilaterales de inversión como política pública encaminada al desarrollo económico" (Consejo Nacional de Política Económica y Social [CoNPEs], 2010, pág. 5). En el mismo sentido, el Plan Nacional de Desarrollo 2006-2010 confirma el apoyo a los acuerdos de inversión (DNP, 2007, pág. 547). Se propone fortalecer los estándares de protección

\footnotetext{
$4 \quad$ En el 2011 se suscribió un Protocolo Modificatorio.

5 Hacia un Estado Comunitario, adoptado mediante la Ley 812 de 2003 (CONPES, 2010).
} 
dados a los inversionistas con la firma de los TBI. Igualmente, busca fortalecer la capacidad del Estado para cumplir con los tratados, y en este sentido prevenir y resolver eventuales controversias internacionales en materia de inversión (CONPES, 2010, pág. 4).

Mamani (2013) encuentra distintas tendencias frente a la inversión en el contexto latinoamericano, y establece que Colombia y Perú tienen políticas favorables a los TBI intentando mejorar el contenido de estos, mientras que Ecuador y Bolivia muestran una tendencia menos favorable, tomando acciones duras como la renegociación.

Las observaciones de Mamani (2013) sobre el contexto latinoamericano concuerdan con la tendencia mostrada en el documento cONPES 2010 y en los Planes Nacionales de Desarrollo, lo cual resalta la importancia de los TBI en la política de promoción de la inversión extranjera en Colombia. El gobierno colombiano ha implementado una política de adopción y negociación de TBI (Universidad del Rosario, 2006), como estrategia para promocionar al país como un destino atractivo para invertir, lo que explica la tendencia de aumento de estos tratados.

Se puede decir que es relevante profundizar en la comprensión de los TBı y las garantías que estos brindan, como lo es la CNMF. En el contexto colombiano es importante promover las investigaciones al respecto pues se desconocen los alcances debido a su novedad y complejidad (CONPES, 2010).

\section{LA CLÁUSULA DE LA NACIÓN MÁS FAVORECIDA EN LOS TRATADOS BILATERALES DE INVERSIÓN}

\section{A. Definición}

La CNMF garantiza que los Estados den al inversionista de otro Estado un trato por lo menos tan favorable a aquel dado a los inversionistas de un tercer Estado. Tiene como consecuencia que si el Estado le da un beneficio relevante a un tercer Estado, automáticamente se extiende al Estado que se beneficia de la cláusula (Dolzer, 2008).

Es importante precisar cuáles son las características que definen la naturaleza jurídica de la cláusula. En primer lugar, es una obligación que tiene su fuente en un tratado específico; así sea incluida en la mayoría de tratados de inversión, no se considera un principio de derecho internacional (UNCTAD, 2010, pág. 22). Al ser parte de un tratado internacional, debe ser interpretada de acuerdo con la Convención de Viena sobre el Derecho de los Tratados (CVDT), principalmente según la regla general de interpretación del artículo 31, ya sea porque el tratado lo establece o por la costumbre internacional de interpretación de tratados (UnCTAD, 2010, pág. 30).

Es un estándar relativo, ya que implica comparar el inversionista con otro al cual se le da un trato distinto (UNCTAD, 1999a). Lo anterior es necesario para determinar si se constituye una situación que sea más favorable para el otro inversionista. Se debe identificar una diferencia 
objetiva en el trato y una desventaja que surja de esta (Unctad, 2010, pág. 24).

El trato que protege la CNMF se sintetiza en que el Estado receptor no puede discriminar de jure o de facto basado en la nacionalidad, siempre que hayan situaciones objetivas similares como una base legítima de comparación (UNCTAD, 2010, pág. 26). En otros términos, se podrían hacer distinciones siempre que no se fundamenten en la nacionalidad, por ejemplo estableciendo regulaciones para la IED en un sector económico determinado.

Igualmente, dentro de su naturaleza jurídica está que se basa en el principio de ejusdem generis, según el cual la cNMF solo se aplica a cuestiones relacionadas con la misma temática o a la misma categoría de temas a los que se refiere la cláusula (UNCTAD, 2010, pág. 24). A propósito se ha dicho que "el principio circunscribe la aplicación de la CNMF a las materias reguladas por el tratado base"6 (UnCTAD, 2010, pág. 24). Es decir, este principio limita de cierta manera las extensiones de garantías que se puedan pretender en la aplicación de la cNmF. Se puede decir que en los casos donde no se haga referencia al tema de manera general en el tratado, podría argumentarse a partir de este principio la no aplicabilidad de la extensión; igualmente, que la aplicación de la cNmF se circunscribe a los temas de inversión.

Por último, se debe recordar que la CNMF en los TBI funciona de manera distinta a como opera

$6 \quad$ Traducción propia. en el contexto del comercio internacional en el marco de la Organización Mundial del Comercio. De hecho, la cláusula se origina en el derecho comercial internacional y se considera una base de las relaciones económicas internacionales (Salomon y Friedrich, 2013). Si bien en los dos contextos buscan conservar la igualdad de condiciones, su aplicación es distinta. En el ámbito comercial es más específica, mientras que en inversión cubre un rango de normas más amplio (UNCTAD, 2010, pág. 29).

\section{B. Aplicación}

La CNMF ha sido vista por algunos como una cláusula que genera ciertas tendencias en los TBI. Para Radi (2007) incluir la CNMF en un tratado de inversión es como traer un Caballo de Troya a una ciudad, ya que esta afecta el equilibrio de los tratados. Otros consideran que la CNMF ha servido como un mecanismo para buscar los beneficios de distintos tratados (treaty shopping), así no se relacionen con la condiciones económicas que garantizan la competencia, y que son el objeto de la protección de la CNMF (Faya, 2008). Para Schill (2009), la cNMF ha creado un proceso de multilateralización del derecho internacional de inversiones, ya que incrementa la uniformidad en la normatividad de la inversión extranjera. Al buscar extender garantías de otros tratados, se armoniza el marco legal de la actividad de los inversionistas.

En la práctica se ha problematizado su entendimiento en casos concretos, pues no están claros los límites sobre la aplicación de la regla a las garantías sustantivas de los tratados 
(Dolzer, 2008). Por una parte, la cnmF se puede interpretar de una manera amplia para que el tratamiento al inversionista incluya no solo disposiciones sustantivas sino procesales (McClure, 2011), como lo sería el consentimiento al arbitraje bajo las reglas del CIADI y precondiciones para este. Por otra parte, se considera que la CNMF solo se aplica para protecciones sustanciales y no a elementos de resolución de conflictos y sus procedimientos (McClure, 2011). A propósito se ha dicho que la aplicación inesperada de la CNMF "ha hecho surgir un debate que hasta ahora no ha terminado y ha generado decisiones diferentes en los laudos arbitrales y en algunos casos inconsistentes" 7 (UNCTAD, 2010, pág. xiv).

Lo anterior muestra el debate que se ha generado frente a las disposiciones relativas a los mecanismos de solución de controversias. Se discute cuál es el alcance de la cNMF, lo que resulta más polémico cuando se trata de asuntos de procedimiento, como son la jurisdicción de los tribunales y los requisitos para acceder al arbitraje internacional.

La relevancia de la discusión se puede ver de manera más clara con las implicaciones de interpretar la CNMF de una u otra manera. En las disputas de inversión se abre la posibilidad de establecer la responsabilidad internacional del Estado, por lo tanto genera preocupación entre estos el hecho de ampliar las bases para el arbitraje internacional con la aplicación de la CNMF (UNCTAD, 2010, pág. 4). En este contexto, si-

$7 \quad$ Traducción propia. guiendo a la UNCTAD (2010), se evidencia cómo los marcos internacionales y nacionales buscan evolucionar aumentando la certeza y la previsibilidad en las condiciones de entrada y operación de los inversionistas extranjeros, lo cual resalta la importancia de la seguridad jurídica en la aplicación de la cNMF.

\section{Categorías}

De acuerdo con la clasificación realizada en el documento sobre la CNMF de la Conferencia de las Naciones Unidas sobre Comercio y DesarroIlo (2010), hay tres aspectos centrales en las CNMF: ámbito de aplicación, protección sustantiva y disposiciones procedimentales. Los dos últimos aspectos son los que han causado mayor discusión, por lo que los TBI recientes han empezado a responder a las implicaciones de las decisiones arbitrales haciendo aclaraciones en la redacción de la CNMF (UNCTAD, 2010). A continuación se explicará cuáles son los elementos principales de cada aspecto.

\section{1. Ámbito de aplicación}

Se compone del objeto de protección (subject matter) y tres elementos de la dimensión sustantiva: establecimiento, excepciones y cualificaciones.

\subsection{Objeto de protección}

En este punto se debe determinar si el trato que garantiza la CNMF será aplicable solo a los inversionistas o a las inversiones. Tiene implicaciones al determinar si lo que se ve afectado con una medida estatal es el inversionista, la inver- 
sión o los dos (Unctad, 2010, pág. 44). Se pueden distinguir CNMF que aplican a inversionistas e inversiones, y aquellas que se limitan solo a los inversionistas.

\subsection{Establecimiento}

Se refiere a las fases de la inversión cubiertas en la protección de la cNMF. En el modelo de postestablecimiento el TBı no cubre la fase de entrada del inversionista, sino que esta se regula por las normas del Estado receptor (UNCTAD, 2010, pág. 43), mientras que el modelo de preestablecimiento sí cubre la fase de entrada, o sea que las condiciones de entrada a las que se enfrenta el inversionista hacen parte del ámbito de aplicación (UNCTAD, 2010, pág. 43). Lo anterior se define por la inclusión de términos que hagan referencia a actividades relacionadas con el establecimiento de la inversión.

\subsection{Excepciones}

En un enfoque de postestablecimiento las excepciones son generales y no limitadas a países específicos. En primer lugar están los beneficios o privilegios otorgados por un Estado debido a acuerdos de uniones aduaneras y otros acuerdos económicos regionales. En segundo lugar, se encuentran excepciones sobre asuntos tributarios, lo cual hace referencia a los acuerdos de doble tributación (UNCTAD, 2010, pág. 47). Es decir, existen cNmF que excluyen de su aplicación acuerdos regionales y aspectos tributarios, mientras otras no se pronuncian al respecto. En el enfoque de preestablecimiento se encuentran más excepciones tanto generales como referidas a países (UNCTAD, 2010, pág. 48).

\subsection{Cualificaciones}

En esta categoría encontramos la precisión de estar en "iguales circunstancias", lo cual se puede ver en el TBI modelo de EE. UU. (U.S. Department of State, 2012), así se considere un componente implícito (UnCTAD, 2010, pág. 54). Igualmente, algunos tratados hacen precisiones sobre el tipo de actividades cubiertas y sobre qué se entiende por tratamiento, y algunas cláusulas adoptan una modalidad de todas las materias (all matters) para tener una cobertura más amplia (UNCTAD, 2010, pág. 55).

\section{Protección sustantiva}

Al aplicar la CNMF se puede buscar una protección sustantiva que no se encuentra en su propio tratado, como podrían ser los estándares de responsabilidad (UNCTAD, 2010). En el caso MTD Equity Sdn Bhd v. Chile se intentó extender aspectos del trato justo y equitativo, y en el EDF International SA v. Argentina la cláusula paraguas. En el caso de cme Czech Republic BV v. Czech Republic, se analizó la extensión de una definición más favorable de compensación justa (Salomon y Friedrich, 2013). En general, en estos casos, las dificultades de interpretación se han debido a que la CNMF no precisa si se extiende o no a estas garantías.

\section{Disposiciones procedimentales}

Las discusiones con respecto a asuntos procedimentales se han centrado en tres temas: precondiciones para el arbitraje, jurisdicción rationae materiae y consentimiento para un foro de 
resolución de controversias específico (Salomon y Friedrich, 2013). Por ejemplo, en el primer caso, los demandantes han intentado sobrepasar precondiciones de arbitraje importando cláusulas de твı que no las contienen.

Al analizar si los medios de solución de controversias entran en el alcance de la CNMF, los límites se pueden determinar de acuerdo con su naturaleza, según el principio ejusdem generis, o según su estructura, la cual depende de los términos usados en su redacción (Herrera, 2009, pág. 42). Herrera (2009) identifica los siguientes tipos de redacción utilizados para definir los límites convencionales de la cNMF:

1. Estipulación expresa de aplicación a las disposiciones relativas al arreglo de diferendos.

2. Utilización de términos generales que cubren, por ejemplo, all matters, pero que no hacen referencia alguna a las disposiciones relativas al arreglo de diferencias.

3. Redacción en términos no generales, aunque guarda silencio en lo relativo a los mecanismos de arreglo de diferencias.

4. Expresión estableciendo que no se aplica a las disposiciones relativas al arreglo de diferencias.

En la doctrina se pueden encontrar distintas posiciones. Para Söderlund (2010), si en el tratado no se establecen exclusiones para la aplicación de la CNMF, en temas como la resolución de disputas, se entiende que la protección no se extiende a estas garantías. Sin embargo, otros opinan que cuando la cNMF se redacta "en términos generales (all matters), incorpora, salvo estipulación expresa en contrario, las cláusulas de arreglo de diferencias" (Herrera, 2009, pág. 45). Los cuestionamientos surgen al preguntarse por los beneficios previstos en distintos tratados, por lo que de manera preliminar se puede sostener, con apoyo en Dolzer (2008), que se aplica la CNMF cuando no contradice el tratado que la contiene y los asuntos que este trata específicamente.

\section{LA CLÁUSULA DE LA NACIÓN MÁS FAVORECIDA EN LOS LAUDOS DE TRIBUNALES ARBITRALES NTERNACIONALES}

\section{A. Los laudos de los tribunales de arbitraje del CIADI}

Se debe iniciar por recordar cuál es la relevancia de los laudos arbitrales del CIADI como fuente de derecho, para luego estudiar las decisiones sobre el tema particular. Conforme a lo previsto por el artículo 42 del Convenio CIADI, sus tribunales deciden "de acuerdo con las normas de derecho acordadas por las partes." Tradicionalmente, las CNMF hacen parte de tratados internacionales, sujetando la decisión de los árbitros a lo previsto en dichos instrumentos de derecho internacional y a las reglas de interpretación que gobiernan tal derecho.

Según el artículo 38 del Estatuto de la Corte Internacional de Justicia (1949), las fuentes de derecho internacional son las convenciones in- 
ternacionales, la costumbre internacional y los principios generales del derecho. El inciso d) establece que la Corte debe aplicar las decisiones judiciales como medio auxiliar para determinar las reglas de derecho. Es decir, que los laudos arbitrales son equivalentes a decisiones judiciales, por lo cual no son una fuente principal de derecho, sino auxiliar.

No obstante, en el contexto del arbitraje de inversión, se ha visto que las decisiones arbitrales son determinantes en los argumentos de las partes y los tribunales. Algunos autores sostienen que los tribunales consistentemente rechazan la noción de un precedente que sea obligatorio legalmente en la forma de stare decisis, sin embargo intentan adherirse a decisiones anteriores de tribunales del CIADI u otros foros, desarrollando así un "de facto case-law" (Reinisch, 2008, pág. 15).

Lo cierto es que se ve una relevancia creciente del papel de las decisiones arbitrales a través de las cuales se interpretan las disposiciones de Ios TBI. En parte, se atribuye a que los TBI contienen estándares generales que en su aplicación se les da un significado más concreto por parte de los tribunales, como ocurre con la cNMF. Igualmente, el carácter público de las decisiones contrasta con otros ámbitos como lo es el derecho comercial internacional, en donde las decisiones son confidenciales en general (Reinisch, 2008, pág. 1). Como lo establece Reinisch (2008), en esta medida, los tribunales del CIADI toman en cuenta las decisiones anteriores para dar forma a un cuerpo más elaborado de derecho de las inversiones internacionales.
Es pertinente igualmente tener en cuenta el papel de las decisiones arbitrales cuando se analiza el derecho internacional de la inversión extranjera en conjunto. Por un lado, se identifica una visión tradicional, en la cual el derecho internacional de la inversión extranjera se agota en la protección al inversionista (Urueña, 2014). Desde esta visión se identifica que puede haber inseguridad jurídica, generada, entre otras causas, por las distintas interpretaciones dadas a las garantías de los TBI, como ocurre con la cNMF. Es problemático, ya que los instrumentos como Ios TBı buscan precisamente dar mayor seguridad jurídica. En este contexto, se han planteado soluciones para mejorar la coherencia del sistema como un todo; por ejemplo, implementando la apelación en el CIADI o creando una Corte Internacional de Arbitraje. El estudio de estas propuestas desborda el enfoque de este trabajo, no obstante, se debe tener presente el contexto en el que se enmarcan las inconsistencias que pueden generar las distintas interpretaciones.

Desde una visión crítica, se ha identificado que más allá de la solución de disputas se puede hablar de un derecho internacional creado por tribunales (Urueña, 2014). Como se estableció anteriormente, cada vez se justifica más preguntarse acerca de la similitud con un precedente judicial, ya que si bien los laudos no son vinculantes para terceros, ${ }^{8}$ siempre son referenciados por otros tribunales. ${ }^{9} \mathrm{Al}$ repetirse los

8 Se debe recordar que, en principio, los efectos son inter partes, como lo establece el artículo 53 del Convenio CIADI.

9 A propósito, es relevante lo dicho en el caso Teinver v. Argentina: "Este Tribunal no está obligado por las decisiones de otros tribunales en el pasado, y resuelve sobre la base del texto del Tratado y los 
criterios mencionados en laudos de inversión, se les da más valor en la argumentación, lo cual podría llegar a generar una jurisprudence constante, ${ }^{10}$ si se crean opiniones comunes en ciertos temas.

Podemos ver que hay una reiteración de argumentos de otros tribunales y apoyo en estos, aunque se debe recordar que no se puede hablar de precedente vinculante como tal (Reinisch, 2008, pág. 5). Algunos consideran que la discreción de los árbitros es amplia, lo que Ileva a que hasta cierto punto el alcance de un tBı no sea claro. Esto es problemático para los Estados, quienes pueden verse condenados a pagar una compensación por incumplir los tratados, y para los inversionistas, al no poder prever los resultados de un litigio (Van Harten, 2007). Debido a que los laudos arbitrales no son una fuente de derecho internacional principal con fuerza vinculante para los tribunales arbitrales, estos mantienen cierta autonomía en sus decisiones, lo que ha llevado a establecer líneas jurisprudenciales con problemas de inconsistencia. Lo anterior será analizado con referencia a la cNMF, para lo cual se precisarán las posiciones de los tribunales en su aplicación y la manera en la que ha influido en el comportamiento de los agentes, principalmente en la definición de los contenidos de la CNMF en los TBI.

argumentos de hecho y de derecho planteados por las Partes. No obstante, el Tribunal reconoce que no resuelve en el vacío."

10 Se entiende como el desarrollo de una opinión jurídica común. Algunos tribunales arbitrales se han referido al término, como ocurrió en los casos AES v. Argentina y SGS v. Philippines (Reinisch, 2008), en donde se dice que debido a los mecanismos de control previstos en el reglamento del CIADI se puede generar en el largo plazo una opinión común en ciertos temas.
Como se puede ver, las decisiones arbitrales tienen un rol determinante no solo en la resolución de las disputas, sino en la creación del derecho internacional de la inversión extranjera como tal. La importancia de los laudos arbitrales se refleja en que estos tienen un efecto doble. De un lado, son la base de la argumentación de decisiones futuras del CIADI, pues en la argumentación de los laudos siempre se hace referencia a las decisiones de otros tribunales. De otro lado, Ios laudos arbitrales afectan el comportamiento de los agentes, ya que los inversionistas y los Estados parten de estas decisiones para comprender las obligaciones internacionales de los TBI. En este sentido, se puede plantear que debido a las extensiones que realizan los tribunales en la aplicación de la cNMF, los Estados han optado por incluir mayores detalles en la cNMF de manera que exprese de forma más clara su voluntad.

\section{B. Posiciones sobre la CNMF}

\section{1. Ámbito de aplicación}

En primer lugar, lo que concierne al ámbito de aplicación, se deben analizar las cualificaciones en la dimensión sustantiva, como se trató en el capítulo II. Más específicamente, se debe elegir el grado de generalidad de los términos en los que se delimita el tratamiento dado al inversionista y las materias que cubre la CNMF.

En el caso Maffezini c. España se aplicó el artículo IV del TBI de Argentina y España, que tiene una disposición sobre la cNmF. Podemos decir 
que es de la forma all matters ya que establece que se aplica a "todas las materias regidas por el presente Acuerdo". El tribunal hace referencia al caso de la Compañía Petrolera Anglo-Iraní, de 1952, en el que la Corte Internacional de Justicia establece que la pretensión de aplicar la CNMF debe sustentarse en el tratado que la contiene, es decir, que la materia a que se aplica la cláusula debe ser establecida por el instrumento básico (Maffezini v. España, párr. 45).

De igual manera, se refiere al caso Ambatielos (1963) tratado por la Comisión de Arbitraje, en el cual se establece que si la cNMF se aplica a "todas las materias relacionadas con el comercio y la navegación", entonces no podrá excluirse la protección de la administración de justicia. Es decir, que en este caso se acepta la protección de garantías sustanciales y procesales cuando la cNMF tiene la forma de all matters. Sin embargo, deja de presente que debe realizarse una interpretación razonable para tener una mejor aproximación a la voluntad de las partes.

Las anteriores decisiones sostienen que la CNMF que comprende todas las materias, cubre los temas que hacen parte del tratado que la contiene. Es de resaltar también que tanto el caso Petrolera Anglo-Iraní como Ambatielos, no fueron decididos por tribunales del CIADI por ser anteriores a su creación. Su inclusión en la argumentación nos muestra que el tribunal consideró pertinente lo dicho por otros entes con respecto a la CNMF, con anterioridad al CIADI. Estas decisiones también son mencionadas en el laudo de Siemens v. Argentina, en donde el tribunal estuvo de acuerdo con la argumentación del caso
Maffezini. De esta manera, se puede ver cómo estas decisiones se incorporan a las líneas de argumentación del CIADI, pues como lo establece el tribunal de Maffezini, son relevantes en la medida en que son parte de los antecedentes de la CNMF.

En el caso Maffezini, España argumentaba que la discriminación que pretendía evitar la cNMF solo se refería a tratamiento material económico y no procedimental. El tribunal estableció que los medios de solución de controversias están estrechamente relacionados con lo sustantivo y que al presentarse una alternativa más favorable en otro tratado, se puede extender por medio de la CNMF teniendo presente el principio ejusdem generis (Maffezini v. España, párr. 55). El tribunal analizó las negociaciones del TBI de Argentina y España y la práctica de España en materia de tratados. Es decir, que cuando se tiene una CNMF del segundo tipo, en la clasificación de Herrera (2009) ${ }^{11}$ aplicaría que: "Hay razones suficientes para concluir que actualmente los arreglos relativos a la solución de controversias están inseparablemente vinculados con la protección de inversionistas extranjeros..." (Maffezini v. España, párr. 54).

Esta posición se ha presentado en otros casos donde el tribunal concluye que las demandantes pueden invocar la cNMF redactada con la fórmula de todas las materias para acceder a las disposiciones de resolución de controversias, ya que esta es "concluyentemente inclusiva" (Teinver v. Argentina, párr. 186).

11 Referencia en la sección II. C. 
En el caso Salini v. Jordania, se señala que cuando la CNMF se refiere al tratamiento en general, all matters, se permite incluir cuestiones procedimentales, sin embargo no ocurre lo anterior en el presente caso, por lo que no se permite la extensión (Gaillard, 2005). En él el tribunal establece que la redacción no se refiere a todas las materias del tratado, ni existe ningún elemento del cual se pueda deducir que las partes tenían la intención de extender la aplicación a solución de controversias (Salini v. Jordania, 2004, párr. 118). Es decir, el tribunal plantea que no se puede realizar la extensión a menos que las partes lo manifiesten de alguna manera en el tratado o que se trate de una cláusula de todas las materias.

Por su parte, se pueden encontrar algunas apreciaciones sobre la cNMF en el caso Tecmed v. México, en donde el tribunal analiza el alegato de la demandada según el cual no hay competencia ratione temporis. El tribunal consideró que en este caso no es posible aplicar el tratado entre Austria y México a través de la cNMF, ya que los asuntos de aplicación en el tiempo se refieren a cuestiones sustantivas y no procesales o jurisdicciones, por lo cual "deben presumirse como especialmente negociadas entre las Partes" pues atañen a "la identificación del régimen sustantivo de protección aplicable al inversor extranjero y muy particularmente del contexto jurídico general" (Tecmed v. México, párr. 69). ${ }^{12}$

12 En este caso, el tribunal interpreta el tratado teniendo en cuenta su apéndice, en donde hay requisitos sobre el acceso al régimen de protección sustancial, lo cual hace concluir que se trata del núcleo de las negociaciones entre las partes (Tecmed v. México, párr. 74).
En el caso $\mathrm{MCl}$ v. Ecuador, las demandantes pretendían que a través de la CNMF se estableciera que el acuerdo tenía efectos retrospectivos limitados al interpretarla junto con el artículo VII sobre la aplicación de otras normas, y de esta manera lograr la protección sustantiva de otro тBI. Sin embargo, el tribunal estableció que no es posible aplicar la cNMF en los términos propuestos, pues el artículo VII hace referencia a otras normas entre las Partes Contratantes, o sea entre Argentina y Ecuador y no entre otros países.

Se puede concluir que tanto en el caso Tecmed v. México como en $\mathrm{MCl}$ v. Ecuador, el tribunal establece límites a la aplicación de la cNMF en temas que afectan las garantías sustantivas, y de manera particular el punto en discusión es la aplicación de un tratado en el tiempo, aspecto que no puede ser alterado con la cNMF.

En el caso Vanessa v. Venezuela hay una referencia a la CNMF cuando el demandante sostiene que el requisito de legalidad del TBı de Canadá y Venezuela no se encuentra en el TBı de Venezuela y Reino Unido, y por lo tanto no se debería aplicar. El tribunal concluye que la CNMF no puede ser utilizada para ampliar la categoría de inversiones a las cuales aplica el TBı de Canadá y Venezuela (Vanessa v. Venezuela, párr. 133), ya que, precisamente, el trato que se deriva de la CNMF se da a las inversiones definidas en el respectivo TBI. Haciendo referencia a las categorías de la sección II.C.1. del presente escrito, podemos ver que en este caso se alude al ámbito de aplicación. La CNMF del TBı de Canadá y Venezuela determina que uno de los objetos de 
protección son las inversiones, ${ }^{13}$ y para poder interpretar su alcance es necesario remitirse a las definiciones del mismo tBI que contiene la cNMF. Lo anterior se reitera en el caso S.G. v. D.R., en donde el demandante también solicita que se aplique la definición de inversión de otro tratado que considera más favorable, pues el tribunal determina que la CNMF aplica al tratamiento que se le dé a las inversiones definidas en el tratado, y no a la definición de inversiones como tal (S.G. v. D.R., párr. 41).

\section{Excepciones sustantivas}

En cuanto a las excepciones, en la dimensión sustantiva del ámbito de aplicación de la CNMF encontramos algunas precisiones que son pertinentes. En el caso Siemens se analiza una cNMF en la que se incluyen excepciones a un trato no menos favorable sobre privilegios acordados en el contexto de uniones aduaneras o económicas y de áreas de libre comercio, y de ventajas garantizadas en acuerdos impositivos (Siemens $v$. Argentina, 2004, párr. 83). En esta oportunidad, el tribunal afirmó que cuando las partes pretendían incluir una limitación absoluta a través de una excepción así lo hicieron, por ejemplo al excluir "medidas dictadas para asegurar el orden público o la seguridad interna o externa, y las ventajas, exenciones o reducciones fiscales" (Siemens v. Argentina, 2004, párr. 83). Es decir, que si bien se establece de manera general la aplicación al "trato" y "actividades", hay distin-

13 En el artículo III 1 y 2 del TBI de Venezuela y Canadá se determina el objeto de protección para el ámbito de aplicación estableciendo que el trato favorable se otorgará a las inversiones, a las ganancias de los inversores y a los inversores. tas precisiones sobre materias excluidas, lo que muestra que no debe restringirse más allá de las excepciones (Siemens v. Argentina, 2004, párr. 85).

En el caso MTD v. Chile el tribunal analiza una CNMF en la que se limita la aplicación al excluir beneficios de acuerdos de cooperación regional y tributaria; y encuentra que se trata de materias ajenas al твı, pero debido a que la cláusula fue redactada en términos generales, las partes consideraron pertinente excluirla (MTD v. Chile, párr. 104).

\section{Disposiciones procedimentales}

Ahora, se deben hacer algunas precisiones sobre el alcance de las disposiciones procedimentales, que pueden dividirse en dos categorías. Por un lado se encuentran casos en donde los demandantes han invocado la CNMF para sobrepasar requisitos procedimentales que constituyen una condición para poder someter el caso al arbitraje internacional, lo cual se puede entender como requisitos de admisibilidad (UNCTAD, 2010, pág. 66). La segunda categoría se refiere al alcance de la jurisdicción, en donde los demandantes han intentado usar la cNmF para que en los casos en que se limita el arbitraje a ciertas materias en el tratado, pueda ser extendido más allá de estas (unctad, 2010, pág. 67).

Dentro de la primera categoría se puede clasificar el caso Maffezini, en donde el demandante invoca la CNMF del TBI de Argentina y España para aplicar una cláusula más favorable del TBı entre Chile y España, y de esta manera tener derecho 
a un tratamiento más favorable en cuanto al agotamiento de recursos internos y poder someter la disputa al arbitraje sin antes presentarla a los tribunales españoles.

Cabe resaltar que en el laudo Maffezini el tribunal establece ciertos límites a la ampliación de los mecanismos de solución de controversias debido a consideraciones de política pública. Dentro de estos se encuentran: revisar si una parte ha condicionado el consentimiento al arbitraje al agotamiento de los recursos internos, verificar si las partes han acordado un mecanismo de solución de controversias con la disposición de fork in the road, un sistema de arbitraje como lo sería el CIADI o un arbitraje altamente institucionalizado que incorpore reglas de procedimiento precisas, como es el Tratado de Libre Comercio de América del Norte (Maffezini v. España, 2000, párr. 63).

De igual manera, en varios laudos contra Argentina los demandantes invocan la CNMF para sobrepasar el requisito procedimental de un periodo de 18 meses para llevar el caso ante la justicia local, ya que otros tratados firmados por dicho país no lo contienen (UNCTAD, 2010). En el caso Gas Natural SDG v. Argentina, el tribunal consideró que de manera similar al caso Maffezini el demandante puede presentar su demanda ante un mecanismo de arbitraje internacional, a pesar del requisito de esperar 18 meses para ir a una corte local (Salomon y Friedrich, 2013). Igualmente estableció que a menos que las partes de un TBI acuerden un mecanismo de solución de controversias distinto, la CNMF debe entenderse como aplicable a la resolución de controversias (Gas Natural SDG V. Argentina).

En el caso Siemens, el tribunal estableció que el acceso a mecanismos de resolución de disputas hace parte del tratamiento dado al inversionista y debe poder ser extendido con la CNMF, y que los términos “'trato' y 'actividades relativas a inversiones' son suficientemente amplios para incluir el arreglo de controversias" (Siemens v. Argentina, 2004, párr. 104).

En cuanto a la segunda categoría, encontramos casos en donde los demandantes han pretendido ampliar la jurisdicción a materias que no fueron previstas para ser presentadas en arbitraje internacional. Es decir, en los que se ha pretendido alterar la jurisdicción ratione materiae a partir de la CNMF (Salomon y Friedrich, 2013).

En Plama v. Bulgaria (2005), se encuentra que el TBı bajo análisis no permite que a través de la CNMF se entienda el consentimiento a tener acceso a la resolución de disputas en el CIADI. En este caso el tribunal presenta una visión mucho más restrictiva con respecto a la aplicación de la CNMF, pues establece que si se aplica la CNMF a la solución de controversias se crea una canasta en la que los inversionistas pueden elegir las disposiciones que prefieran entre distintos TBI, lo cual puede llevar a una situación caótica en la que el Estado se ve enfrentado a disposiciones de resolución de disputas que no acordó (Plama v. Bulgaria). En otras palabras, el tribunal consideró que tal aplicación disminuye la seguridad jurídica al reducir la certeza sobre el contenido de los tratados. 
La anterior posición ha sido sostenida por otros tribunales, como sucedió en el caso Telenor $v$. Hungría, donde se estableció que no se puede pretender que la cNmF extienda la jurisdicción del tribunal a categorías de controversias más allá de aquellas que son previstas en el TBI, cuando no hay un lenguaje claro respecto a que tal es la intención de las partes. En este caso las partes limitan la resolución de controversias a asuntos de expropiación, por lo que el tribunal consideró que se había hecho una elección deliberada de limitarlo a estas categorías (Telenor v. Hungría, 2006, párr. 97).

En principio, podría pensarse que lo dicho en esta categoría aplicaría solamente a aquellos casos en que se quiera ampliar el ratione materiae y no para todos los casos sobre asuntos procedimentales; sin embargo, en el caso Telenor el tribunal realiza observaciones de carácter más general que pueden entrar en contradicción con las posiciones de otros tribunales acerca del ámbito de aplicación y disposiciones procedimentales. En esta ocasión ${ }^{14}$ el tribunal estableció que de acuerdo con los términos de la CNMF, según los cuales "las inversiones deben tener un tratamiento que no sea menos favorable que el acordado a un inversionista de otro Estado", y con las reglas de interpretación de la CVDT, la CNMF se refiere solo a derechos sustantivos y no hay una base para importar garantías procesales también (Telenor v. Hungría, 2006, párr. 92). Lo anterior parece no estar acorde con lo decidido por el tribunal en los casos Maffezini

14 Se debe tener en cuenta también que en este caso, Telenor cita en su argumentación como demandante los casos Maffezini y Siemens (Telenor c. Hungría, 2006, párr. 85). y Gas Natural, en los que consideró que al no preverse un mecanismo alterno de solución de controversias, la cNMF puede extenderse a este ámbito.

\section{LA CLÁUSULA DE LA NACIÓN MÁS FAVORECIDA EN LOS TRATADOS BILATERALES DE INVERSIÓN VIGENTES PARA COLOMBIA}

Habiendo identificado las distintas posiciones respecto de la CNMF en las decisiones arbitrales, se pasará a analizar de manera más específica cómo ha sido acordada en los TBI vigentes para Colombia. Se busca comparar la redacción y exclusiones de la CNMF para posteriormente identificar cómo se puede garantizar mayor seguridad jurídica.

Algunos autores consideran que no se le ha dado un enfoque apropiado al estudio de la CNMF, y que este se debe concentrar en cuál es el ámbito de aplicación de provisiones específicas sobre asuntos procedimentales (Radi, 2007). Por lo anterior, este capítulo se enfoca en aspectos más específicos, concretamente en el análisis de la redacción de la cNMF en los tratados.

Dentro de los TBI vigentes para Colombia se escogieron dos para profundizar y otros a los que solo se harán referencia. Se analizarán los tratados con EE. UU. y Suiza en razón a que la cnmF se pactó de manera distinta en cada uno. En el TLC con EE. UU. se hace una exclusión expresa de los mecanismos de solución de controversias, mientras que en el de Suiza se excluyen aspec- 
tos comerciales y de doble tributación. Esta diferencia permite comparar los estilos utilizados en la formulación de las cláusulas, así como analizar y explicar sus diferencias.

De igual manera se debe tener en cuenta la importancia de los flujos de IED provenientes de estos países en la economía colombiana. EE. UU. es el país del cual se recibe la mayor cantidad de IED, concepto que para el 2014 representó el 17\% (Proexport, 2014a). Al tercer trimestre de 2013 Suiza fue el segundo país con los mayores flujos y en el 2014 pasó al tercer lugar (Procolombia, 2015).

\section{A. Tratado con EE. UU.}

En primer lugar se debe precisar que estamos frente a un TLC, ${ }^{15}$ Acuerdo de Promoción Comercial entre la República de Colombia y Estados Unidos de América, que cuenta con 23 capítulos, el décimo dedicado a la inversión. El acuerdo es de gran relevancia por el impacto que tiene en distintos sectores de la economía colombiana, dado que EE. UU. es el principal socio comercial. Por lo anterior, su negociación y aprobación fue un proceso que generó distintas discusiones y expectativas debido a su alcance. Hubo 14 rondas de negociaciones y fue suscrito finalmente el 22 de noviembre de 2006. Mediante la Ley 1143 de 2007 quedó incorporado a la legislación colombiana, y a través de la sentencia C-750 de 2008 la Corte Constitucional realizó el control constitucional previo, declarándolo ajustado a la Carta Fundamental (MCIT, 2012).

15

Referencia en la sección I.B.1 sobre concepto y evolución de los TBI.
Los respectivos gobiernos realizaron el canje de notas en la VI Cumbre de las Américas. En Colombia el acuerdo se promulgó mediante el Decreto 993 del 15 de mayo de 2012, fecha en la que entró en vigencia (мсіт, 2012).

El artículo 10.4 sobre Trato de Nación Más Favorecida, tiene el siguiente contenido:

1. Cada parte concederá a los inversionistas de otra Parte un trato no menos favorable que el que conceda, en circunstancias similares, a los inversionistas de cualquier otra Parte o de un país que no sea Parte en lo referente al establecimiento, adquisición, expansión, administración, conducción, operación y venta u otra forma de disposición de inversiones en su territorio.

2. Cada parte concederá a las inversiones cubiertas un trato no menos favorable que el que conceda, en circunstancias similares, a las inversiones en su territorio de inversionistas de cualquier otra Parte o de cualquier país que no sea Parte en lo referente al establecimiento, adquisición, expansión, administración, conducción, operación y venta u otra forma de disposición de inversiones. ${ }^{2}$

La nota 2 que aparece al final del párrafo 2 dice:

Para mayor certeza, el trato "con respecto al establecimiento, adquisición, expansión, administración, conducción, operación y venta u otra forma de disposición de inversiones", a que hacen referencia los párrafos 1 y 2 del artículo 10.4, no incluye mecanismos de solución de controversias, tales como los señalados en la sección $B$, que se encuentren estipulados en acuerdos comerciales o de inversiones. 
Como se puede ver, en el artículo se hace una distinción entre inversionistas e inversiones para determinar el objeto de protección. Esto puede obedecer a que los dos son definidos en el tratado, ${ }^{16}$ y limitarse a uno solo podría resultar en una reducción de la protección cuando el inversionista o la inversión no encajen en una de las definiciones. Lo anterior corresponde a la forma en que usualmente se redacta la CNMF para los tratados que firma EE. UU., ya que de acuerdo con el TBı modelo de dicho país, para 2012, como se puede ver en el artículo 4, la CNMF presenta la misma estructura y redacción.

De igual manera, vemos que se define el tratamiento respecto del cual se asume la obligación de trato de nación más favorecida, pues la cNMF opera "en lo referente al establecimiento, adquisición, expansión, administración, conducción, operación y venta u otra forma de disposición de inversiones en su territorio." Es decir, no se utiliza la fórmula general de inclusión de todas las materias, por lo cual se puede decir que es más específico que la fórmula de all matters. Igualmente, se puede identificar la adopción de un modelo de preestablecimiento, ya que se incluyen las primeras fases de la inversión, esto es las relacionadas con su establecimiento, lo cual responde a una tendencia desde los años 90 en los tBı de EE. UU. y Canadá, de cubrir esta fase (UNCTAD, 2010).

Llama la atención la inclusión de la nota de pie de página, ya que esta no se encuentra en el

16 Como se vio en la revisión de laudos del CIADI, la aplicación de la CNMF parte de la definición de inversión o inversionista del tratado que la contiene. tratado modelo. Esta actúa como una aclaración para la interpretación de los términos de la cláusula, en la que se dice que la cNMF no incluye las disposiciones sobre resolución de controversias, y podría entenderse como una reacción a las decisiones del CIADI, ya que en casos como Maffezini el tribunal estableció que la solución de controversias tiene una estrecha relación con la protección general de los derechos del inversionista. Igualmente, se estableció que se debe realizar una interpretación razonable. Esto implica que al redactar la cláusula de manera general, queda un margen en el cual los Estados no están seguros de cuál pueda ser el efecto al ser interpretada por un tribunal, lo cual representa un riesgo, ya que hay incertidumbre sobre cuál pueda ser el efecto de la cNMF.

En la documentación del Ministerio de Comercio, Industria y Turismo, concretamente en el Libro Blanco del TLC, se encuentra que en los resultados de la Ronda XIII, ${ }^{17}$ uno de los temas acordados fue el pie de página en el que se excluyen los mecanismos de solución de controversias (Mciт, 2005a). Esto evidencia que fue un elemento convenido expresamente en las negociaciones de esta Ronda, correspondientes a paquetes simples y complejos y de definición de asuntos más sensibles (McIт, 2005b). ${ }^{18}$

Al incluir el pie de página Maffezini, como lo establece textualmente, se quiere dar mayor

17 Realizada en Washington entre el 14 y 22 de noviembre de 2005.

18 Igualmente, en materia de inversión en esta Ronda se concluyó: "El capítulo incluye un acuerdo entre las dos naciones, que atraerá inversiones hacia nuestro país, resguardando nuestra legislación. Hay garantías recíprocas para ambos" (MCIт, 2005c). 
certeza a los efectos de esta cláusula. Debido a que las decisiones de tribunales del CIADI han permitido la extensión de la protección a materias sustantivas y procedimentales, los Estados han reaccionado a dichas decisiones judiciales redactando cláusulas más detalladas.

Cabe preguntarse qué sucedería en el caso que la CNMF no tuviera la excepción. Como se ha visto en las decisiones arbitrales, va a depender de la interpretación que se realice y de la voluntad de las partes en su práctica de tratados. Se podría decir que, en este caso, la cláusula no presenta la forma de all matters, por lo tanto difiere de la analizada en el caso Maffezini, y no se debería permitir la extensión. Lo anterior es similar a lo ocurrido en el caso Salini v. Jordania, en el que el tribunal no aceptó la aplicación de la solución de Maffezini, ya que la cláusula no expresaba que se debía aplicar a todas las materias. Sin embargo, esto queda sujeto a la interpretación que realice el tribunal, por lo que resulta más precavido incluir la aclaración, para que de esta manera sea más evidente la voluntad de las partes de excluir la aplicación en esta área.

Se puede ver que en el tratado celebrado por Colombia con Canadá, se utiliza la misma redacción que en el TLC con EE. UU. En este caso advertimos que incluso la exclusión Maffezini hace parte de la cláusula como tal y no de un pie de página, como se observa en el artículo 804. Igualmente, se encuentra que la excepción aparece en el tratado con China, en el inciso 3 del artículo 3, al establecer que no incluye mecanismos para la solución de disputas de inversión, y en el TLC con Chile en el capítulo 9 sobre inversión, en donde se decidió realizar la aclaración en un anexo. También la encontramos en el APPRI con Perú, en el artículo 3.3, y en el TLC del Triángulo Norte.

Con respecto a la cNMF en el tratado con EE. UU. se encuentra que al incluir el pie de página Maffezini se garantiza mayor seguridad jurídica, ya que se prevé que el tribunal no pueda extenderlo a mecanismos de solución de controversias. Si se establece que la cNMF no tiene un ámbito de aplicación general, sería difícil incluir los mecanismos de solución de controversias, así no se hiciera la precisión en pie de página. Al prever la exclusión de forma general se evita la incertidumbre en el tema que puede haber en las decisiones arbitrales.

\section{B. Tratado con Suiza}

El TBI con Suiza, es decir, el Convenio entre la República de Colombia y la Confederación Suiza sobre la promoción y la protección recíproca de inversiones, fue firmado en el 2006 y entró en vigencia en octubre de 2009. Se debe hacer la distinción entre este tratado y aquel vigente con Suiza y Liechtenstein desde julio de 2011, el Acuerdo de Libre Comercio entre la República de Colombia y los Estados AELC (EFTA), el cual tiene un capítulo sobre inversión, pero no incluye una CNMF. ${ }^{19}$

19 En el artículo 5.7 de este tratado se establece: "Las disposiciones de este Capítulo se entenderán sin perjuicio de los derechos y obligaciones de las Partes en virtud de otros acuerdos internacionales, de los cuales Colombia y uno o varios Estados AELC sean partes. Se entiende que cualquier mecanismo de solución de controversias en un acuerdo de protección de inversiones del cual Colombia y un Estado AELC sean parte no es aplicable a las presuntas violaciones de este Capítulo." 
En la CNMF incluida en el TBI con Suiza se realiza una exclusión de las uniones comerciales y de tributación, la cual no está presente en el capítulo de inversión del TLC con EE. UU. Como se puede ver en la cNmF:

ARTÍCULO 4. PROMOCIÓN Y TRATAMIENTO.

(1) Cada una de las Partes deberá proteger dentro de su territorio las inversiones hechas de acuerdo a sus leyes y regulaciones por inversionistas de la otra Parte y no podrá perjudicar con medidas no razonables o discriminatorias el mantenimiento, uso, disfrute, extensión, venta, y, llegado el caso, la liquidación de dichas inversiones.

(2) Cada Parte deberá garantizar un tratamiento justo y equitativo en su territorio a las inversiones de los inversionistas de la otra Parte. Este tratamiento no podrá ser menos favorable que aquel dado por cada una de las Partes a las inversiones hechas dentro de su territorio por sus propios inversionistas, o que aquel dado a los inversionistas de la nación más favorecida, si este último tratamiento es más favorable.

(3) Si una Parte acuerda ventajas especiales a inversiones de un tercer Estado por virtud de un acuerdo que establezca un área de libre comercio, una unión aduanera o un mercado común o un acuerdo regional similar o en virtud de un acuerdo para evitar la doble tributación, no deberá estar obligado a acordar dichas ventajas a inversiones de inversionistas de la otra Parte.

De manera preliminar, llama la atención que la CNMF en este tratado no se redacta de forma independiente, sino que en el numeral dos (2) se articula con los principios de trato nacional y trato justo y equitativo. Lo anterior puede generar contradicciones, ya que por un lado el trato justo y equitativo parte de un estándar de trato fijo, y el cumplimiento del estándar no se ve afectado por el trato que se le dé a otros inversionistas o inversiones (UnCTAD, 1999b). Por otro lado, el trato nacional y la cNMF son estándares relativos, como fue precisado en la sección 2.1 del presente trabajo. Al respecto se ha establecido que cuando se ofrece el "trato justo y equitativo combinado con trato nacional y trato de la nación más favorecida, se les da a los inversionistas una protección contingente y no contingente" (UNCTAD, 1999b). Es decir, algunos lo ven como protecciones que se complementan.

De acuerdo con los términos del artículo 4 del TBI de Colombia y Suiza, parece condicionarse que tanto el trato nacional y el trato de nación más favorecida, entendidos como principios de no discriminación, aplican al contenido del trato justo y equitativo. ${ }^{20}$ Este estándar ha sido materia de numerosas consideraciones para definir su contenido, lo cual debe ser tenido en cuenta al interpretar la CNMF, pues según las pautas de interpretación de la cVDT, se debe interpretar de acuerdo con el sentido corriente de los términos y su contexto. Es decir, se debe hacer una remisión al alcance del trato justo y equitativo para comprender la cNMF en este caso.

En el tratado no se excluyen los mecanismos de solución de controversias, sin embargo se pue-

20 De acuerdo con Dolzer (2008), este se basa en las expectativas legítimas de los inversionistas al momento de realizar la inversión y el debido proceso en la toma de decisiones que puedan afectar al inversionista. 
de pensar que la CNMF debe interpretarse junto con el principio de trato justo y equitativo, de acuerdo con la redacción del artículo 4, lo cual puede llegar a ampliar su ámbito de aplicación. Además, combinar los estándares puede crear confusiones respecto del contenido de las garantías y su interpretación.

Con respecto a la excepción del numeral 3 sobre acuerdos de libre comercio y uniones aduaneras, es relevante tener en cuenta la referencia al caso MTD v. Chile, pues la cNMF también se redacta con el principio de trato justo y equitativo. El tribunal concluye que materias que entren dentro del trato justo y equitativo podrían entenderse como parte de la CNMF si no se realiza la exclusión, debido a la naturaleza más amplia de dicho trato.

Igualmente, si la CNMF no se redacta junto con el trato justo y equitativo, las materias de acuerdos comerciales y tributarios podrían no incluirse debido al principio de ejusdem generis. Al no excluir estos temas, podría considerarse que son materias que desbordan el tratamiento dado al inversionista ya que tienen un alcance más general. En principio son pactados en tratados independientes, o distintos capítulos en el caso de un TLC, que no están sujetos a las definiciones de inversionistas e inversiones, las cuales son la base de la protección bajo un TBI. Al respecto, se encuentra que "ha sido posición del Gobierno Colombiano que los asuntos tributarios se traten de manera autónoma e independiente, ya que es un tema objeto de otro tipo de acuerdos y por lo tanto, se excluye su aplicación de los acuerdos de inversión" (coN-
PES, 2001, págs. 8-9). En este sentido podría decirse que no harían parte del tratamiento que protege la CNMF.

En la misma tendencia del TBI con Suiza encontramos el твı con España, en donde en el artículo 3 sobre la CNMF, se excluye:

Cualquier preferencia o privilegio resultante de su asociación o participación, actual o futura, en una zona de libre comercio, unión aduanera, económica o monetaria o en cualquier otra forma de organización económica regional o acuerdo internacional de características similares (Acuerdo entre la República de Colombia y el Reino de España para la Promoción y Protección Recíproca de Inversiones, 2005).

Igualmente, la encontramos en el tratado con China en el inciso 4 del artículo 3. En el TLc con México vemos que también se realiza una excepción en el inciso 4 del artículo 17-03, en la que se dice que las partes no están obligadas a extender ventajas otorgadas en virtud de un tratado para evitar la doble tributación.

De acuerdo con la UNCTAD (2004) las excepciones de acuerdos económicos regionales pueden depender del grado de apertura de los acuerdos regionales de sus miembros con respecto a países no miembros, lo cual puede tener un impacto en la política de negociación. Su extensión estaría determinada por el grado de integración de los países, es decir, de si cuentan con acuerdos comerciales o tributarios, y si puede establecerse que entran dentro del ámbito de aplicación. La mayoría de los países que pertenecen a una organización de integración económica regional 
(OIER $)^{21}$ incluyen una cláusula al respecto en los BIT, como ocurre en el artículo 4.4 del tratado modelo de Suiza, y se considera que una excepción es el Tratado Modelo de EE. UU. (UNCTAD, 2004, pág. 44). Lo anterior se refleja en los tratados de inversión de los cuales hace parte CoIombia, ya que la precisión se encuentra en el BIT con Suiza y no en el TLC con EE. UU.

\section{CONCLUSIONES}

Como conclusión debe precisarse inicialmente, que en Colombia la IED cobra cada vez más importancia al ser una fuente de financiación que ha crecido notablemente y que afecta distintas variables en la economía, como son la productividad, el empleo y la acumulación de activos externos. En este contexto, el aumento en la firma de los TBI se ha visto como un mecanismo que permite dar ciertas garantías a los inversionistas mejorando sus condiciones de inversión, y abre la posibilidad de someter las disputas al arbitraje internacional de inversión.

La CNMF tiene un rol determinante en la dinámica de los TBI, al permitir la exigibilidad de obligaciones que no fueron pactadas inicialmente en los tratados bajo el principio de no discriminación por razón de la nacionalidad en condiciones equivalentes. Sin embargo, en la práctica no son claros los límites de las garantías que entran en su protección.

Al analizar los laudos arbitrales del CIADI se hizo evidente que, si bien hay inconsistencias en el

21 Regional Economic Integration Organization (REIO) tema, se pueden establecer distintas líneas de argumentación que van a depender del preciso contenido y objeto de las cláusulas. Como se vio, en el famoso laudo Maffezini la extensión se condicionó a que la cláusula fuera all matters, por lo cual en el caso Salini se decidió no otorgar la extensión. Es decir, al mirar las características particulares de las cláusulas pueden resolverse aparentes contradicciones. Igualmente, los tribunales han limitado su aplicación cuando se trata del tiempo del tratado y la definición del objeto de protección. Sin embargo, los laudos sobre disposiciones procedimentales pueden considerarse inconsistentes, pues aquellos que tratan los requisitos previos de acceso al arbitraje tienden a tener una concepción más amplia sobre el alcance de la cNMF, lo cual contrasta con aquellos que se han pronunciado sobre las materias de jurisdicción. En cuanto a las excepciones sustantivas, se encuentra que cuando la CNMF se redacta con el trato justo y equitativo las excepciones pueden ayudar a limitar el alcance más general de la cláusula.

Se puede confirmar que los efectos de la CNMF dependen de su preciso contenido y redacción. En la medida en que se excluyan ámbitos de aplicación, un tribunal arbitral no va a poder extenderla a disposiciones que los Estados no tenían previstas. Cada vez los Estados están más conscientes de que la cNMF puede ser una fuente de obligaciones internacionales indeseadas y, por lo tanto, actúan para limitar su ámbito de aplicación (Salomon y Friedrich, 2013). Esto se refleja claramente en los tratados vigentes para Colombia, en donde se ha visto que la mayoría limitan la aplicación de mecanismos de solu- 
ción de controversias, como ocurre con el de EE. UU., o la extensión de mecanismos de doble tributación y acuerdos comerciales, en el caso de Suiza. Sin embargo, existen TBı vigentes para Colombia que excluyen no solo los mecanismos de solución de controversias, sino también los acuerdos comerciales y tributarios, como sucede con el tratado con China.

Ya que el alcance de la cNMF depende de los términos en que se pacte, excluir ámbitos de aplicación garantiza mayor seguridad jurídica. Las exclusiones deben verse con mayor detalle en las cláusulas que se pacten de manera general, como cuando se incluyen todas las materias del tratado.

Resulta de utilidad estar más conscientes de las implicaciones de esta cláusula para la firma de futuros TBI y comprender mejor sus beneficios y riesgos. En este sentido se recomienda que los Estados pacten expresamente los ámbitos que quieran excluir, teniendo en cuenta la amplitud del ámbito de aplicación de la cláusula.

\section{Referencias}

1. Acuerdo bilateral para la promoción y protección de inversiones entre el Gobierno de la República de Colombia y el Gobierno de la República Popular China. (2012).

2. Acuerdo de Libre Comercio entre la República de Colombia y Canadá. (2011).

3. Acuerdo de Libre Comercio entre la República de Colombia y la República de Chile - Pro- tocolo adicional al Acuerdo de Complementación Económica para el Establecimiento de un Espacio Económico Ampliado entre Colombia y Chile (ACE 24). (2009).

4. Acuerdo de Libre Comercio entre la República de Colombia y los Estados aelc (efta). (2011).

5. Acuerdo de Promoción Comercial entre la República de Colombia y Estados Unidos de América. (2012).

6. Acuerdo entre el Gobierno de Canadá y el Gobierno de la República de Venezuela para la promoción y la protección de inversiones. (1996).

7. Acuerdo entre el Gobierno de la República del Perú y el Gobierno de la República de CoIombia para la Promoción y Protección Recíproca de Inversiones. (2007).

8. Acuerdo entre la República de Colombia y el Reino de España para la Promoción y Protección Recíproca de Inversiones. (2005).

9. Agudelo, M. I. (1997). La inversión extranjera en la macroeconomía colombiana (19901995). En P. De Lombaerde, La inversión extranjera en Colombia: régimen jurídico y análisis económico. Bogotá: Centro de Investigaciones Academicas Civilizar. Universidad Sergio Arboleda.

10. [Ambatielos]. (1956). Decisión de la Comisión de Arbitraje establecida para la demanda de Ambatielos entre Grecia y el 
Reino Unido. En Maffezini v. España, Naciones Unidas: Reports of International Arbitral Awards, XII, 1963, pág. 91.

11. Banco de la República. Circular Reglamentaria Externa dcin 83 del Departamento de Cambios Internacionales.

12. Bonilla, S. y Castro, R. (2006). A Law and Economics Analysis of International Investment Treaties: Latin America. 2nd Annual Conference of the Italian Society for Law and Economics: side Working Papers.

13. Comisión Económica para América Latina y el Caribe [Cepal]. (2006). Capítulo II. Políticas activas para atraer inversión extranjera directa: experiencia internacional y situación de América Latina y el Caribe. En cepal, La inversión extranjera en América Latina y el Caribe (págs. 69-93). Santiago de Chile: Naciones Unidas.

14. Comisión Económica para América Latina y el Caribe [Cepal]. (2013). La inversión extranjera directa en América Latina y el Caribe. Santiago de Chile: Naciones Unidas.

15. Consejo Nacional de Política Económica y Social [conpes]. (2001). Lineamientos de políticas para las negociaciones internacionales de acuerdos de inversión extranjera. Documento Conpes 3135. Bogotá: Departamento Nacional de Planeación.

16. Consejo Nacional de Política Económica y Social [Conpes]. (2010). Fortalecimiento de la estrategia del Estado para la prevención y atención de controversias internacionales de inversión. Documento Conpes 3684. Bogotá: Departamento Nacional de Planeación.

17. Convención de Viena sobre el Derecho de Ios Tratados. U.N. Doc A/CONF.39/27 1155 U.N.T.S. 331. Viena, 1969.

18. Convenio entre la República de Colombia la Confederación Suiza sobre la Promoción y Protección Recíproca de Inversiones. (2009).

19. Convenio sobre arreglo de diferencias relativas a inversiones entre Estados y nacionales de otros Estados. Centro Internacional de Arreglo de Diferencias Relativas a Inversiones (ciadi). (1966).

20. Decreto-Ley 444 de 1967. Sobre régimen de cambios internacionales y de comercio exterior. Colombia. Diario Oficial. Año ClI. N. 32189. 6, abril, 1967. Pág. 1.

21. Departamento Nacional de Planeación. (2007). Plan Nacional de Desarrollo 20062010. Estado comunitario: Desarrollo para todos (t. II.). Bogotá: Autor.

22. Departamento Nacional de Planeación. (2011). Plan Nacional de Desarrollo 20102014. Más empleo, menos pobreza y más seguridad (t. I.). Bogotá: Autor.

23. Dolzer, R. (2008). Principles of International Investment law. Nueva York: Oxford University Press. 
24. Esquivel G. y Larraín F. (2001). ¿Cómo atraer inversión extranjera directa? Center for International Development at Harvard University.

25. Estatuto de la Corte Internacional de Justicia [Naciones Unidas]. (1949).

26. Faya, A. (2008). The Most Favored Nation Clause in International Investment treaties. Journal of International Arbitration, 25(1), 89-102.

27. Gaillard, E. (2005). Establishing jurisdiction through a most-favored-nation clause. New York Law Journal. 233 (105).

28. Garavito, A., Iregui, A. M. y Ramírez, M. (2012). Inversión extranjera directa en CoIombia: Evolución reciente y marco normativo. Borradores de Economía. Núm. 713. Bogotá: Banco de la República.

29. [Gas Natural v. Argentina] Gas Natural sdg, S.A. v. la República Argentina. Decisión del Tribunal sobre preguntas preliminares sobre jurisdicción. Caso No. ARB/03/10 (2005).

30. Granato, L. y Nahuel, C. (2007). Derecho internacional, ¿protección del inversor extranjero y acuerdos bilaterales, quo vadis? Universidad eafit, 43(148), 25-41.

31. Herrera, V. (2009). Efectos sorpresivos de la cláusula de la nación más favorecida (cnmf) en materia de inversiones extranjeras. Civilizar, 9(16), 41-56.
32. Kalin, Y. (2009). Documentos cede. fdi in CoIombia: Policy and Economic Effects. Bogotá: Ediciones Uniandes.

33. Ley 812 de 2003. Por la cual se aprueba el Plan Nacional de Desarrollo 2003-2006, Hacia un Estado comunitario. Junio 27 de 2003. Colombia. DO n. ${ }^{\circ} 45231$.

34. Lizarazo, L. (1997). Acuerdos Bilaterales de Promoción y Protección a la Inversión (appi). En P. De Lombaerde, La inversión extranjera en Colombia: Régimen jurídico y análisis económico. Bogotá: Centro de Investigaciones Academicas Civilizar. Universidad Sergio Arboleda.

35. [Maffezini v. España] Emilio Agustín Maffezini v. El Reino de España. Decisión del tribunal sobre excepciones a la jurisdicción. Caso ciadi No. ARB/97/7 (2000).

36. Mamani Prieto, W. (2013). La dinámica de los acuerdos internacionales de inversión en los andinos. Anuario Mexicano de Derecho Internacional, XIII, 549-582.

37. [MCl v. Ecuador] $\mathrm{MCl}$ Power Group and New Turbine Inc v. Ecuador. Laudo. Caso ciadi No ARB/03/6 (2007).

38. McClure, M. (2011). Most Favoured Nation Clauses - No favoured view on how they should be interpreted. From Kluwer Arbitration Blog: http://kluwerarbitrationblog.com/

39. Ministerio de Comercio, Industria y Turismo [mcit]. (2005a). tlc con Estados Unidos: re- 
sultados xiii ronda (Washington, 14 al 22 de noviembre de 2005). Bogotá.

40. Ministerio de Comercio, Industria y Turismo. (2005b). Tratado de Libre Comercio Colombia-Estados Unidos. Presentaciones públicas - Despacho jefe negociador. Presentación informe ronda xiii (Diciembre 14 de 2005). Bogotá.

41. Ministerio de Comercio, Industria y Turismo. (2005c). Palabras de Hernando José Gómez, jefe negociador de Colombia del tlc, al término de la xiii ronda (Noviembre 23 de 2005). Washington, D.C.

42. Ministerio de Comercio, Industria y Turismo. (2012). Acuerdo de Promoción Comercial entre la República de Colombia y Estados Unidos de América. Obtenido de Mincomercio, Industria y Turismo: < http://www.tlc. gov.co/publicaciones.php?id=14853>

43. Ministerio de Comercio, Industria y Turismo. (2014). Acuerdos internacionales de inversión vigentes. Obtenido de Mincomercio, Industria y Turismo: <http://www.tlc.gov.co/ publicaciones. php?id=6420>

44. Moosa, I. A. (2002). Foreign Direct Investment: theory, evidence and practice. New York: Palgrave.

45. [MTD v. Chile] MTD Equity Sdn. Bhd. and MTD Chile S.A. v. Republic of Chile. Award. Case No. ARB/01/7 (2004).
46. [Plama v. Bulgaria] Plama Consortium Limited v. Republic of Bulgaria. Decision on jurisdiction. icsid Case No. ARB/03/24 (2005).

47. Procolombia. (2015). Reporte trimestral de inversión extranjera directa en Colombia a tercer trimestre de 2014.

48. Proexport. (2011). Relaciones entre Colombia y Suiza - Inversión a 2014. Disponible en: <http://www.proexport.com.co/noticias/relaciones-entre-colombia-y-suiza-inversion>

49. Proexport. (2012). Ficha país: Estados Unidos. Disponible en: <http://www.colombiatrade.com.co/sites/default/files/ficha_ pais_estados_unidos.pdf>

50. Proexport. (2014a). Reporte trimestral de inversión extranjera directa en Colombia a 2014. Obtenido de Proexport Colombia: <http://www.proexport.com.co/ node/1541>

51. Proexport. (2014b). Estadísticas de inversión extranjera directa en Colombia a 2014. Disponible en: <http://www.proexport.com. co/node/1541>

52. Radi, Y. (2007). The Application of the Most-Favoured-Nation Clause to the Dispute Settlement provisions of Bilateral Investment Treaties: Domesticating the "Trojan Horse". European Journal of International Law, 18(4), 757-774. 
53. Reinisch, A. (2008). The Role of Precedent in icsid Arbitration. Austrian Arbitration Yearbook, 495-510.

54. Reino Unido v. Irán. Caso de la Anglo-Iranian Oil Co. (Excepción preliminar). Corte Internacional de Justicia (1952).

55. [Salini v. Jordania] Salini Costruttori S. p .A. and Italstrade S. p. A. v. The Hashemite Kingdom of Jordan. Decision on jurisdiction. icsid Case No. ARB/02/13 (2004).

56. Salomon, C. y Friedrich, S. (2013). How most favoured nation clauses in bilateral investment treaties affect arbitration. From Practical Law Arbitration: http://uk.practicallaw. com/

57. Schill, S. W. (2009). Mulitilateralizing Investment Treaties through Most-Favored-Nation Clauses. Berkeley Journal of International Law, 27(2).

58. [S.G. v. D.R.] Société Générale v. Dominican Republic. Award on Preliminary Objections to Jurisdiction. LCIA Case No UN 7927 (2008).

59. [Siemens v. Argentina] Siemens A.G. v. República de Argentina. Decisión sobre jurisdicción. Caso ciadi No. ARB/02/8 (2004).

60. Söderlund, C. (2010). Most Favoured Nation (MFN) Clauses in Bilateral Investment Treaties. En Fernández-Ballesteros, M. A. and Arias, D. (Eds.), Liber Amicorum Bernardo Cremades (págs. 1121-1130). España: La Ley.
61. [Tecmed v. México] Técnicas Medioambientales Tecmed SA v. México. Laudo. Caso ciadi No ARB(AF)/00/2 (2003).

62. [Teinver v. Argentina] Teinver S. A., Transportes de Cercanías S. A. and Autobuses Urbanos del Sur S. A. v. La República Argentina. Decisión sobre jurisdicción. Caso ciadi No. ARB/09/1 (2012).

63. [Telenor v. Hungría] Telenor Mobile Communications A.S. v. The Republic of Hungary. Award. icsid Case No. ARB/04/15 (2006).

64. Tratado de libre comercio entre los Estados Unidos Mexicanos y la República de Colombia. Protocolo Modificatorio, 2011. (1995).

65. United Nations Conference on Trade and Development [unctad]. (1999a). Trends in international investment agreements: an overview. unctad Series in issues in international investment agreements. New York and Geneva: United Nations.

66. United Nations Conference on Trade and Development [unctad]. (1999b). Fair and Equitable Treatment. unctad Series in issues in international investment agreements. New York and Geneva: United Nations.

67. United Nations Conference on Trade and Development [unctad]. (2004). The reio Exception in $\mathrm{mfn}$ Treatment Clauses. unctad Series in issues in international investment agreements. New York and Geneva: United Nations. 
68. United Nations Conference on Trade and Development. (2006). Trends and Emerging Issues Series on International Investment Policies for Development. En S. Bonilla y R. Castro, A Law and Economics Analysis of International Investment Agreements: Latin America. Roma: Italian Society of Law and Economics.

69. United Nations Conference on Trade and Development [unctad]. (2009). El papel de los acuerdos internacionales de inversión en la atracción de inversión extranjera directa hacia los países en desarrollo. Colección de publicaciones de la unctad sobre las políticas internacionales de inversión para el desarrollo. Nueva York y Ginebra: Naciones Unidas.

70. United Nations Conference on Trade and Development. (2010). Most-favored-nation treatment. unctad Series on Issues in International Investment Agreements II. Ginebra \& Nueva York: United Nations.

71. Universidad del Rosario. (2006). Tendencias actuales de la inversión extranjera en Co-
Iombia. Fascículo 11. Tomo 1. Universidad, Ciencia y Desarrollo. Bogotá: Universidad del Rosario.

72. Urueña, R. (Octubre 2014). El derecho de la inversión extranjera como gobernanza global. En R. Urueña (Dir.), Aproximaciones críticas al derecho internacional de la inversión extranjera. Bogotá: Universidad de los Andes.

73. U.S. Department of State. (2012). U.S. Model Bilateral Investment Treaty. Disponible en: <http://www.state.gov/e/eb/ifd/bit/index.htm>

74. Van Harten, G. (2007). Investment Treaty Arbitrtion and Public Law. Oxford: Oxford University Press.

75. [Vanessa v. Venezuela] Vannessa Ventures Ltd. v. Venezuela. Award. ICSID Case No ARB (AF)/04/6 (2013).

76. World Bank. (2011). A guide to the World Bank (Third ed.). Washington D. C.: World Bank. 